\title{
Resolution dependence of uncertainties in gridded emission inventories: a case study in Hebei, China
}

\author{
Bo Zheng ${ }^{1}$, Qiang Zhang ${ }^{2}$, Dan Tong ${ }^{2}$, Chuchu Chen ${ }^{2}$, Chaopeng Hong ${ }^{2}$, Meng Li ${ }^{2}$, Guannan Geng², Yu Lei ${ }^{3}$, \\ Hong $\mathrm{Huo}^{4}$, and Kebin $\mathrm{He}^{1,5}$ \\ ${ }^{1}$ State Key Joint Laboratory of Environment Simulation and Pollution Control, School of Environment, \\ Tsinghua University, Beijing 100084, China \\ ${ }^{2}$ Ministry of Education Key Laboratory for Earth System Modeling, Department of Earth System Science, \\ Tsinghua University, Beijing 100084, China \\ ${ }^{3}$ The Atmospheric Environment Department, Chinese Academy for Environmental Planning, Beijing 100012, China \\ ${ }^{4}$ Institute of Energy, Environment and Economy, Tsinghua University, Beijing 100084, China \\ ${ }^{5}$ State Environmental Protection Key Laboratory of Sources and Control of Air Pollution Complex, Beijing 100084, China
}

Correspondence to: Qiang Zhang (qiangzhang@tsinghua.edu.cn) and Kebin He (hekb@tsinghua.edu.cn)

Received: 9 October 2016 - Published in Atmos. Chem. Phys. Discuss.: 24 October 2016

Revised: 21 December 2016 - Accepted: 30 December 2016 - Published: 20 January 2017

\begin{abstract}
Gridded emission inventories are essential inputs for chemical transport models and climate models. Spatial proxies are applied to allocate emissions from regional totals to spatially resolved grids when the exact locations of emissions are absent, with additional uncertainties arising due to the spatial mismatch between the locations of emissions and spatial proxies. In this study, we investigate the impact of spatial proxies on the accuracy of gridded emission inventories at different spatial resolutions by comparing gridded emissions developed from different spatial proxies (proxy-based inventory) with a highly spatially disaggregated bottom-up emission inventory developed from the extensive use of locations of emitting facilities (bottom-up inventory) in Hebei Province, China. We find that proxy-based inventories are generally comparable to bottom-up inventories for grid sizes larger than $0.25^{\circ}$ because spatial errors are largely diminished at coarse resolutions. However, for gridded emissions with finer resolutions, large positive biases in urban centers and negative biases in suburban and rural regions are identified in proxy-based inventories and are then propagated into significant biases in urban-scale chemical transport modeling. Compared to bottom-up inventories, the use of proxy-based emissions exhibits similar modeling results, with biases varying from 3 to $13 \%$ when predicting surface concentrations of different pollutants at $36 \mathrm{~km}$ resolution and an additional $8-73 \%$ at $4 \mathrm{~km}$ resolution. The res-
\end{abstract}

olution dependence of uncertainties in proxy-based gridded inventories can be explained by the decoupling of emission facility locations from spatial surrogates, especially because industry facilities tend to be located away from urban centers. This distance results in a divergence between emission distributions and the allocation of proxies on smaller grids. The decoupling effects are weakened when the grid size increases to cover both urban and rural regions. We conclude that proxy-based inventories are of sufficient quality to support regional and global models (larger than $0.25^{\circ}$ in this case study); however, to support urban-scale models with accurate emission inputs, bottom-up inventories incorporating the exact locations of emitting facilities should be developed instead of proxy-based inventories.

\section{Introduction}

Gridded emission inventories have emerged as a critical component of atmospheric chemistry and climate models. The importance of these inventories has been driven by the advent of regional chemical transport models on different spatial scales. As the key inputs, spatial representations of emission estimates containing errors can be propagated into modeled concentrations, affecting subsequent studies based on those chemical transport models. 
Gridded emission inventories can be developed using two methods: bottom-up estimates and proxy-based estimates with downscaling techniques. Bottom-up estimates rely on massive spatial information such as point sources, detailed censuses, and traffic statistics. For large point sources, emissions can be estimated for each individual facility and then mapped at high resolutions (e.g., Zhao et al., 2008; Liu et al., 2015). For on-road emissions, high-resolution mapping can be achieved using road-specific traffic count data on spatial scales ranging from $500 \mathrm{~m}$ to $10 \mathrm{~km}$ (e.g., Gately et al., 2013, 2015; McDonald et al., 2014). The bottom-up inventory methods above rely on mass data inputs, which are accurate but difficult to extend through all sectors and regions. For example, Gurney et al. (2009) developed the Vulcan inventory to quantify fossil fuel $\mathrm{CO}_{2}$ emissions for the contiguous USA at a resolution of $10 \mathrm{~km}$. This data product was built upon the best available data sources through all sectors throughout the USA, including point, nonpoint, and airport datasets with additional emission monitoring data from individual facilities.

The proxy-based method relies on spatial proxies to build emission inventories in gridded form. Because they require relatively less data, proxy-based approaches are widely used for developing gridded emission inventories. Proxies such as population and nighttime lights have been used to derive gridded emissions (e.g., Raupach et al., 2010; Oda and Maksyutov, 2011; Wang et al., 2013), which are implicitly assumed to be resolution-independent at sizes ranging from district level to grid cells. However, this correlation is likely sensitive to fine-scale spatial resolutions, which introduce uncertainties in high-resolution emission mapping. Gurney et al. (2009) highlighted the spatial biases inherent in a population-based gridded emission inventory due to the decoupling of emissions and population at $0.1^{\circ}$. Oda and Maksyutov (2011) presented the uncertainties in a nighttime light-based inventory due to the saturation errors in nighttime light data at $1 \mathrm{~km}$. Gately et al. $(2013,2015)$ found that the spatial correlation between the per-mile $\mathrm{CO}_{2}$ emissions of motor vehicles and population density changed from positive to negative when population density increased (cutoff point of approximately 2000 persons $\mathrm{km}^{-2}$ ). The studies above suggest that nonlinearities exist between emissions and spatial proxies on fine scales. The downscaling method with fixed correlation can involve large uncertainties in proxy-based gridded emissions, especially at high resolutions.

The uncertainties in proxy-based gridded emission inventories are sensitive to spatial resolution. Recent efforts suggest that the spatial errors of proxy-based $\mathrm{CO}_{2}$ emission inventories tend to increase as spatial resolutions rise (e.g., Gurney et al., 2009; Rayner et al., 2010; Oda and Maksyutov, 2011; Wang et al., 2013; Asefi-Najafabady et al., 2014) because spatial proxies are decoupled from emissions at fine resolutions; however, the influence of uncertainties in gridded emission inventories of air pollutants and their propaga- tion in atmospheric chemistry models is not considered. This shortcoming hampers high-resolution air pollution modeling when proxy-based inventories are used because the grid size suitable for constraining the uncertainties is unknown.

This paper aims to investigate how resolutions influence uncertainties in gridded emission inventories of air pollutants and the subsequent atmospheric chemistry modeling. The spatial resolution dependence of uncertainties in gridded emission inventories is quantified using multi-resolution emission inventories, a chemical transport model, and in situ measurements. We use Hebei Province in China, where a detailed bottom-up emission inventory is available. We first develop gridded emission inventories for Hebei at the resolution of $1 \mathrm{~km}$ using proxy-based and bottom-up methods and then compare the two datasets at multiple aggregated spatial resolutions. The Community Multi-scale Air Quality (CMAQ) model is driven by the two gridded emission datasets to explore how uncertainties affect the performance in predicting the surface concentrations of different air pollutants.

\section{Methodology}

\subsection{Gridded emission inventories}

\subsubsection{Bottom-up inventory}

We used the bottom-up method to develop a high-resolution emission inventory for Hebei Province in 2013 (denoted by HB-EI). The emission sources were subdivided into more than 700 sector, fuel (or product), and technology combinations of source categories and aggregated into five sectors (power, industry, residential, transportation, and agriculture). Each source category was classified as point, nonpoint, or mobile, with a different emission accounting method applied to each category.

Point sources were stationary emitting sources inventoried at a facility level. The power and industry sectors were treated as point sources, from which the emissions were calculated using the following:

Emis $_{i, s}=A_{i} \times \mathrm{EF}_{i, s} \times \prod_{n}\left(1-\eta_{i, n, s}\right)$,

where $i$ represents the emitting facility, $s$ represents air pollutants (i.e., $\mathrm{SO}_{2}, \mathrm{NO}_{x}$, VOCs (volatile organic compounds), $\mathrm{NH}_{3}, \mathrm{CO}, \mathrm{CO}_{2}, \mathrm{PM}_{2.5}, \mathrm{BC}, \mathrm{OC}, \mathrm{PM}_{10}$, and TSP (particulate matter with aerodynamic diameter of $100 \mu \mathrm{m}$ or less)), $A$ is the activity rate, EF is the unabated emission factor, $n$ represents an air pollution control device, and $\eta_{i, n, s}$ is the removal efficiency of pollutant $s$ by control device $n$ installed at facility $i$. The point sources were located according to their latitudinal and longitudinal coordinates. The locations of large point sources were checked and corrected by visual inspection in Google Maps. Large point sources included power and heating plants, large industrial boilers ( $\geq 24.5 \mathrm{MW})$, and 
Table 1. Proxies used for spatial distributions of emissions in HB-EI and MEIC ${ }^{\mathrm{a}}$.

\begin{tabular}{|c|c|c|c|c|c|}
\hline \multirow{2}{*}{ Sector } & \multirow{2}{*}{ Subsector } & \multicolumn{2}{|c|}{ HB-EI } & \multicolumn{2}{|c|}{ MEIC } \\
\hline & & Province to county & County to grid & Province to county & County to grid \\
\hline \multicolumn{2}{|l|}{ Power } & \multicolumn{2}{|c|}{ Point source } & \multicolumn{2}{|c|}{ Point source } \\
\hline \multicolumn{2}{|l|}{ Industry } & \multicolumn{2}{|c|}{ Point source } & Industrial GDP ${ }^{b}$ & Urban population $^{\mathrm{d}}$ \\
\hline \multirow{2}{*}{ Residential } & Urban & Residential coal use $^{c}$ & Urban population $^{\mathrm{d}}$ & Urban population $^{\mathrm{b}}$ & Urban population $^{\mathrm{d}}$ \\
\hline & Rural & $\begin{array}{l}\text { Residential coal and/or } \\
\text { biofuel use }\end{array}$ & Rural population $^{\mathrm{d}}$ & Rural population ${ }^{\mathrm{b}}$ & Rural population $^{\mathrm{d}}$ \\
\hline \multirow{4}{*}{ Transportation } & On-road ${ }^{\mathrm{e}}$ & Vehicle numbers & $\begin{array}{l}\text { Road network; } \\
\text { traffic flow data }\end{array}$ & Vehicle numbers & $\begin{array}{l}\text { Road network; } \\
\text { traffic flow data }\end{array}$ \\
\hline & $\begin{array}{l}\text { Non-road: } \\
\text { agriculture }\end{array}$ & Machine power ${ }^{b}$ & Rural population $^{\mathrm{d}}$ & Machine power ${ }^{\mathrm{b}}$ & Rural population $^{\mathrm{d}}$ \\
\hline & $\begin{array}{l}\text { Non-road: } \\
\text { construction }\end{array}$ & Construction area $^{c}$ & Urban population $^{\mathrm{d}}$ & Total GDP & Urban population $^{\mathrm{d}}$ \\
\hline & $\begin{array}{l}\text { Non-road: } \\
\text { other source }\end{array}$ & Total population ${ }^{\mathrm{b}}$ & Total population ${ }^{\mathrm{d}}$ & Total population ${ }^{\mathrm{b}}$ & Total population ${ }^{\mathrm{d}}$ \\
\hline Agriculture & $\begin{array}{l}\text { Fertilizer } \\
\text { Livestock }\end{array}$ & $\begin{array}{l}\text { Fertilizer use }{ }^{\mathrm{b}} \\
\text { Livestock amount }^{c}\end{array}$ & $\begin{array}{l}\text { Rural population }{ }^{\mathrm{d}} \\
\text { Rural population }^{\mathrm{d}}\end{array}$ & $\begin{array}{l}\text { Fertilizer use }^{\mathrm{b}} \\
\text { Meat consumption }^{\mathrm{b}}\end{array}$ & $\begin{array}{l}\text { Rural population } \\
\text { Rural population }^{\mathrm{d}}\end{array}$ \\
\hline $\begin{array}{l}\text { The proxies in bold } \\
\text { Data source: Natio } \\
\text { Data source: statist } \\
\text { Data source: popul } \\
\text { Data source: Zheng }\end{array}$ & $\begin{array}{l}\text { ed in HB-EI } \\
\text { reau of Statis } \\
\text { m local agen } \\
\text { lata (Oak Ric } \\
\text { (2014). }\end{array}$ & $\begin{array}{l}\text { different from those used in } \\
\text { 14). }\end{array}$ & 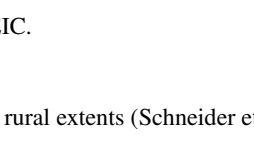 & & \\
\hline
\end{tabular}

manufacturing factories of coke, iron, steel, cement, and flat glass. These sites constituted $90 \%$ of the energy demand from all the point sources. For the other point sources, the coordinates of registered addresses were used directly.

Nonpoint or area sources were stationary emitting sources inventoried at a province level, from which emissions exit from diffuse sources without identifiable stacks. The residential, non-road transportation and agriculture sectors were estimated as nonpoint sources using the following:

$$
\begin{aligned}
\operatorname{Emis}_{j, k, m, s}= & A_{j, k} \times X_{j, k, m} \times E F_{j, k, m, s} \\
& \times \sum_{n}\left(C_{j, k, m, n} \times\left(1-\eta_{n, s}\right)\right),
\end{aligned}
$$

where $j$ represents sector, $k$ represents fuel or product, $m$ represents technology, $X$ is the fraction of activity rates contributed by a specific technology, $C$ is the penetration of a specific pollution-control technology, and the other parameters are the same as in Eq. (1). The nonpoint sources were allocated to a $30^{\prime \prime} \times 30^{\prime \prime}$ grid in two steps. First, the provincial emission totals were distributed to each county based on county-level activity statistics. For example, we used the residential coal and biofuel use of each county to allocate residential emissions. Second, county emissions were allocated to grids based on spatial proxies, such as urban or rural extents (Schneider et al., 2009) and population (Oak Ridge Na- tional Laboratory, 2013). The parameters used in nonpoint source emission distributions are summarized in Table 1.

Mobile sources referred to the on-road transportation sector and were estimated using the method established by Zheng et al. (2014). The county-specific vehicle activity and emission factors were simulated and multiplied to calculate county-level vehicle emissions. County emissions were downscaled to a $30^{\prime \prime} \times 30^{\prime \prime}$ grid using a geographic information system (GIS) road atlas and traffic flow statistics specific to different vehicle and road types (Zheng et al., 2014).

\subsubsection{Proxy-based inventory}

We used the data from the Multi-resolution Emission Inventory for China (MEIC) as the proxy-based estimate. MEIC is a technology-based emission model framework developed by Tsinghua University (http://www.meicmodel.org). This model was built on the foundation laid by the same group responsible for the present study (e.g., Zhang et al., 2007, 2009; Lei et al., 2011), with high-resolution mapping of emissions for power plants (Liu et al., 2015) and on-road vehicles (Zheng et al., 2014).

The emission source categorization in MEIC is the same as that in HB-EI. Emissions of power plants were estimated for each unit using Eq. (1). The on-road transportation sector was estimated following the method established by Zheng et 

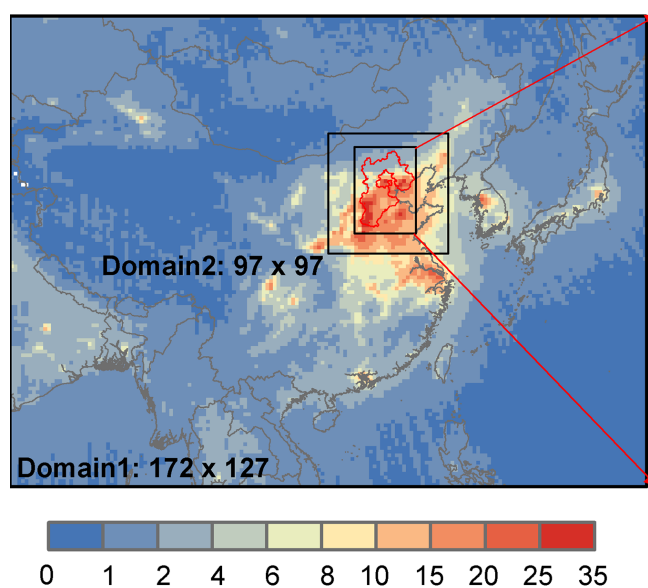

(a) Vertical column density of tropospheric $\mathrm{NO}_{2}$ $\left(10^{15}\right.$ molecules $\left.\mathrm{cm}^{-2}\right)$

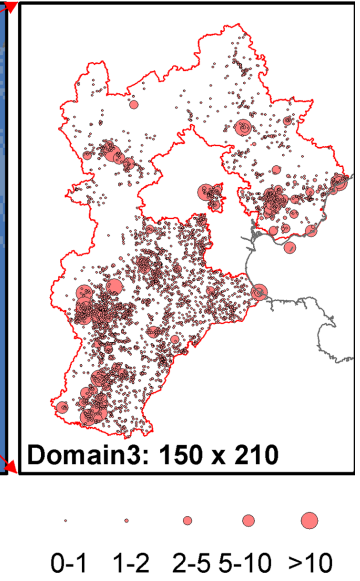

(b) $\mathrm{NO}_{\mathrm{x}}$ emissions $\left(\mathrm{Gg}-\mathrm{NO}_{2}\right)$

Figure 1. Triple-nested domains of the CMAQ simulation: (a) spatial extent of triple-nested domains with OMI (ozone monitoring instrument)-derived $\mathrm{NO}_{2}$ column densities (Boersma et al., 2011) in background, (b) domain 3 with $\mathrm{NO}_{x}$ emissions from point sources in HB-EI inventory.

al. (2014) as the bottom-up inventory. The industrial, residential, non-road transportation, and agricultural sectors were estimated as nonpoint sources using Eq. (2) with activity rates and emission factors at the provincial level. Emission totals from nonpoint sources were allocated to grid cells using different spatial proxies. The proxies used for MEIC are also presented in Table 1 and compared with HB-EI. For example, in MEIC, the residential sector used county population to split provincial emissions by county instead of residential energy consumption used in HB-EI.

In this work, we used Hebei emissions from 2013 from MEIC v1.2 and scaled the emission magnitude to match the HB-EI inventory by source category. This approach can support the magnitude-independent comparison to reflect the discrepancies in the spatial distribution of gridded emissions. Multi-resolution gridded emissions aggregated from the $30^{\prime \prime} \times 30^{\prime \prime}$ grids were used to assess the resolution dependence of uncertainties in the gridded emission inventory.

\subsection{Chemical transport model}

\subsubsection{Model configuration}

The WRF-CMAQ system was used to evaluate emission inventories and assess how uncertainties in gridded emission inventories influenced atmospheric chemical modeling. CMAQ v5.0.1 (http://www.cmascenter.org/cmaq/) was applied in this work, which was driven by assimilated meteorological fields from the Weather Research and Forecasting (WRF) model v3.5.1 (http://www.wrf-model.org/). The model configurations were determined following the method established in our previous work (Zheng et al., 2015). We used the updated carbon bond gas-phase mechanism with an updated toluene mechanism (Whitten et al., 2010), aerosol module 6 (AERO6), and ISORROPIA v2.1 inorganic chemistry (Fountoukis and Nenes, 2007). The aqueous-phase chemistry method used in this study was the updated mechanism of the Regional Acid Deposition Model (Walcek and Taylor, 1986; Chang et al., 1987). Photolytic rates were calculated in line using simulated aerosol and ozone concentrations. The ACM (asymmetrical convective model) methodology was adopted in the cloud module to compute convective mixing for aerosols. The configurations above were evaluated in Zheng et al. (2015).

Anthropogenic emissions outside Hebei Province were taken from MEIC for China (http://www.meicmodel.org) and MIX for the other Asian countries (Li et al., 2015). Emission inputs were processed on simulation domains from their native resolutions $\left(30 \mathrm{~s} \times 30 \mathrm{~s}\right.$ for MEIC and $0.25^{\circ} \times 0.25^{\circ}$ for MIX). Other emissions, such as biomass burning, sea salt, and biogenic VOCs, were taken from various models and datasets following the method established by Zheng et al. (2015).

The boundary and initial conditions were processed from the GEOS-Chem model output (Bey et al., 2001) using the tool developed by Henderson et al. (2014).

\subsubsection{Simulation design}

Two full-year simulations of 2013 were conducted using MEIC (denoted by S1) and HB-EI (denoted by S2), both at triple-nested domains $(36,12$, and $4 \mathrm{~km})$, with the finest resolution focusing on Hebei Province (Fig. 1). We also conducted a sensitivity simulation (denoted by S3) for January, April, July, and October using the adjusted HB-EI emissions by changing $\sim 20 \%$ point sources into nonpoint source estimates to assess the influence of highly spatially resolved emission sources on atmospheric chemistry model- 
ing. We aggregated the emissions from small industrial boilers $(\leq 24.5 \mathrm{MW})$ into provincial totals and then distributed the totals onto grid cells using the same spatial proxies as those used in the industrial sector in MEIC.

The model performances were evaluated against groundbased measurements. We compared the annual daily mean of simulation and observation for the criteria air pollutants and we calculated mean bias (MB) and normalized mean bias (NMB) to evaluate modeling results.

\subsection{In situ measurements}

The ground-based observations in Hebei were acquired from the China National Environmental Monitoring Center (http: //106.37.208.233:20035/), which published hourly concentrations of $\mathrm{SO}_{2}, \mathrm{NO}_{2}, \mathrm{CO}, \mathrm{O}_{3}, \mathrm{PM}_{2.5}$, and $\mathrm{PM}_{10}$ from 53 monitoring stations over Hebei in 2013. This dataset was built and maintained by the Ministry of Environmental Protection in China and is used as the official dataset for national air-quality management. The ground-based stations are primarily located in urban centers because they are designed to assess population exposures in the densest areas.

\section{Results}

\subsection{Emission inventories: bottom-up versus proxy-based}

In the HB-EI inventory, we estimated the anthropogenic emissions of Hebei Province in 2013 as follows: $1.4 \mathrm{Tg} \mathrm{SO}_{2}$, 2.0 $\mathrm{Tg} \mathrm{NO}_{x}, \quad 1.5 \mathrm{Tg}$ VOCs, $\quad 0.5 \mathrm{Tg} \mathrm{NH}_{3}, \quad 16.8 \mathrm{Tg} \mathrm{CO}$, 827.2 $\mathrm{Tg} \mathrm{CO}_{2}, \quad$ 2.7 Tg TSP, $\quad 1.3 \mathrm{Tg} \mathrm{PM}_{10}, \quad 0.9 \mathrm{Tg} \mathrm{PM}_{2.5}$, $0.1 \mathrm{Tg} \mathrm{BC}$, and $0.2 \mathrm{Tg} \mathrm{OC}$. The magnitudes of emissions in MEIC were scaled to match HB-EI by emission source; therefore, the discrepancies between MEIC and HB-EI were primarily attributed to the differences in spatial distributions. The MEIC inventory represented a mixture of data sources from downscaled province-level emissions and point sources (i.e., power plants), in which $25 \% \mathrm{SO}_{2}$, $\mathrm{NO}_{x}$, and $\mathrm{CO}_{2}$ emissions were identified as point sources (Fig. 2a). Conversely, more than $70 \%$ emissions in the HB-EI inventory were inventoried as point sources (Fig. 2b), and the remaining emissions were constrained by road- and county-level activities.

The discrepancy in emission shares of point sources varied by pollutant between MEIC and HB-EI. For pollutants that dominated emissions by industrial combustion and production (e.g., $\mathrm{CO}_{2}, \mathrm{SO}_{2}$, and $\mathrm{NO}_{x}$ ), $\mathrm{HB}$-EI presented a much larger share of point source emissions than MEIC, while for the pollutants mainly emitted from diffuse sources (e.g., VOCs, $\mathrm{NH}_{3}, \mathrm{BC}$, and $\mathrm{OC}$ ), the two datasets presented similar contributions from point sources. These findings suggested that the nonlinearities in $\mathrm{CO}_{2}$ emissions and spatial proxy covariance identified in early studies (e.g., Gurney et al., 2009; Rayner et al., 2010; Oda and Maksyutov, 2011; Wang et al., (a) MEIC

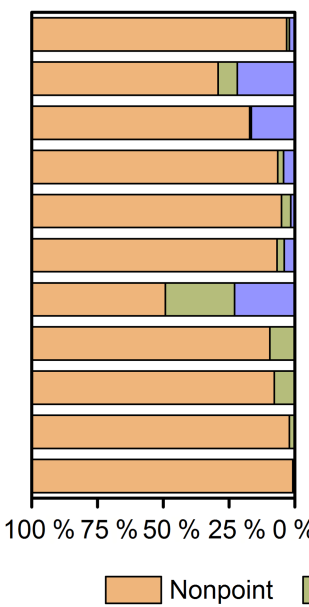

(b) HB-EI

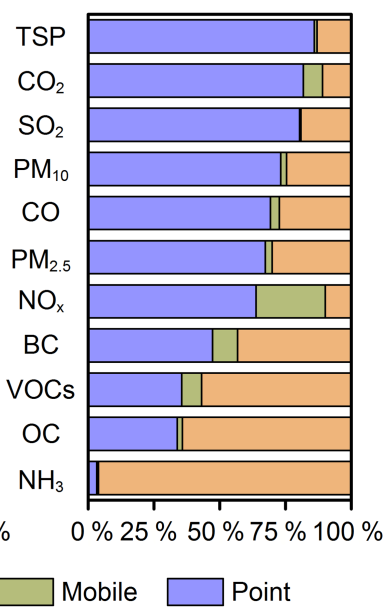

Figure 2. Emission percentages contributed by point, nonpoint, and mobile sources in Hebei Province: (a) the MEIC inventory, (b) the HB-EI inventory.

2013; Asefi-Najafabady et al., 2014) may have diverged for different air pollutants.

\subsection{Resolution dependence of uncertainties in the gridded emission inventory}

Table 2 shows the comparison between the gridded emissions of the bottom-up inventory (HB-EI) and the proxybased inventory (MEIC) over the Hebei region at different resolutions. Following the method established by Rayner et al. (2010), three metrics were adopted for comparison: (1) spatial correlation $(R)$, which quantifies the correspondence of spatial patterns; (2) summed absolute difference (SAD), which is the sum of the absolute difference for the whole domain; and (3) relative summed absolute difference (RSAD), which is calculated as the SAD divided by total emissions over the domain. For the pollutants of which emissions are dominated by point sources, the two gridded inventories agreed well at coarse resolutions (grid size larger than $0.25^{\circ}$ ), while the differences tended to increase when grid size decreased, indicating more spatial biases involved in proxy-based inventories at high spatial resolutions. For example, the resolutions of 0.05 and $0.1^{\circ}$ produced normalized bias (RSAD) as large as $80-100 \%$, results that were much higher than the uncertainties in total emissions (e.g., 20-40\% for $\mathrm{SO}_{2}$ and $\mathrm{NO}_{x}$ ). For the pollutants of which emissions are dominated by nonpoint sources (e.g., $\mathrm{NH}_{3}$ ), the two inventories agreed well regardless of spatial resolution because they shared the same spatial proxies.

Figure 3 compares the spatial distributions of gridded emissions using $\mathrm{NO}_{x}$ as an example. Figure $3 \mathrm{a}-\mathrm{d}$ presents $\mathrm{NO}_{x}$ emission distributions in HB-EI at different spatial resolutions, and Fig. 3e-h presents the differences between the two inventories. At high resolutions $\left(0.05\right.$ and $\left.0.1^{\circ}\right)$, MEIC 
Table 2. Comparison of gridded emissions from MEIC and HB-EI at different resolutions.

\begin{tabular}{|c|c|c|c|c|c|c|c|c|c|c|c|c|c|c|c|}
\hline & \multicolumn{5}{|c|}{$R^{\mathrm{a}}$} & \multicolumn{5}{|c|}{$\mathrm{SAD}^{\mathrm{b}}(\mathrm{Tg})$} & \multicolumn{5}{|c|}{$\operatorname{RSAD}^{\mathrm{c}}(\%)$} \\
\hline & $0.05^{\circ}$ & $0.1^{\circ}$ & $0.25^{\circ}$ & $0.5^{\circ}$ & $1.0^{\circ}$ & $0.05^{\circ}$ & $0.1^{\circ}$ & $0.25^{\circ}$ & $0.5^{\circ}$ & $1.0^{\circ}$ & $0.05^{\circ}$ & $0.1^{\circ}$ & $0.25^{\circ}$ & $0.5^{\circ}$ & $1.0^{\circ}$ \\
\hline TSP & 0.25 & 0.44 & 0.71 & 0.84 & 0.84 & 3.56 & 2.92 & 2.09 & 1.56 & 1.28 & 136 & 111 & 80 & 60 & 49 \\
\hline $\mathrm{CO}_{2}$ & 0.59 & 0.66 & 0.76 & 0.91 & 0.92 & 783 & 628 & 439 & 287 & 200 & 96 & 77 & 54 & 35 & 24 \\
\hline $\mathrm{SO}_{2}$ & 0.54 & 0.68 & 0.81 & 0.9 & 0.89 & 1.33 & 1.06 & 0.75 & 0.57 & 0.47 & 99 & 79 & 56 & 42 & 35 \\
\hline $\mathrm{PM}_{10}$ & 0.31 & 0.49 & 0.73 & 0.87 & 0.86 & 1.38 & 1.13 & 0.83 & 0.64 & 0.52 & 111 & 91 & 67 & 51 & 42 \\
\hline $\mathrm{CO}$ & 0.23 & 0.4 & 0.69 & 0.79 & 0.77 & 18.66 & 16.34 & 12.63 & 10.63 & 9.24 & 114 & 100 & 77 & 65 & 56 \\
\hline $\mathrm{PM}_{2.5}$ & 0.31 & 0.49 & 0.73 & 0.86 & 0.85 & 0.91 & 0.76 & 0.57 & 0.45 & 0.38 & 103 & 86 & 64 & 51 & 42 \\
\hline $\mathrm{NO}_{x}$ & 0.78 & 0.83 & 0.87 & 0.94 & 0.95 & 1.34 & 1.04 & 0.77 & 0.5 & 0.39 & 68 & 52 & 39 & 25 & 20 \\
\hline $\mathrm{BC}$ & 0.33 & 0.49 & 0.71 & 0.88 & 0.9 & 0.11 & 0.09 & 0.07 & 0.05 & 0.04 & 77 & 65 & 51 & 39 & 32 \\
\hline VOCs & 0.72 & 0.84 & 0.91 & 0.96 & 0.97 & 0.8 & 0.65 & 0.5 & 0.37 & 0.28 & 53 & 44 & 34 & 25 & 19 \\
\hline OC & 0.42 & 0.59 & 0.79 & 0.91 & 0.93 & 0.12 & 0.1 & 0.08 & 0.06 & 0.05 & 56 & 48 & 38 & 30 & 24 \\
\hline $\mathrm{NH}_{3}$ & 0.93 & 0.97 & 0.99 & 1 & 1 & 0.04 & 0.03 & 0.03 & 0.02 & 0.02 & 7 & 6 & 5 & 4 & 3 \\
\hline
\end{tabular}

a $R$ : spatial correlation coefficient.

b SAD: summed absolute difference.

c RSAD: relative summed absolute difference.
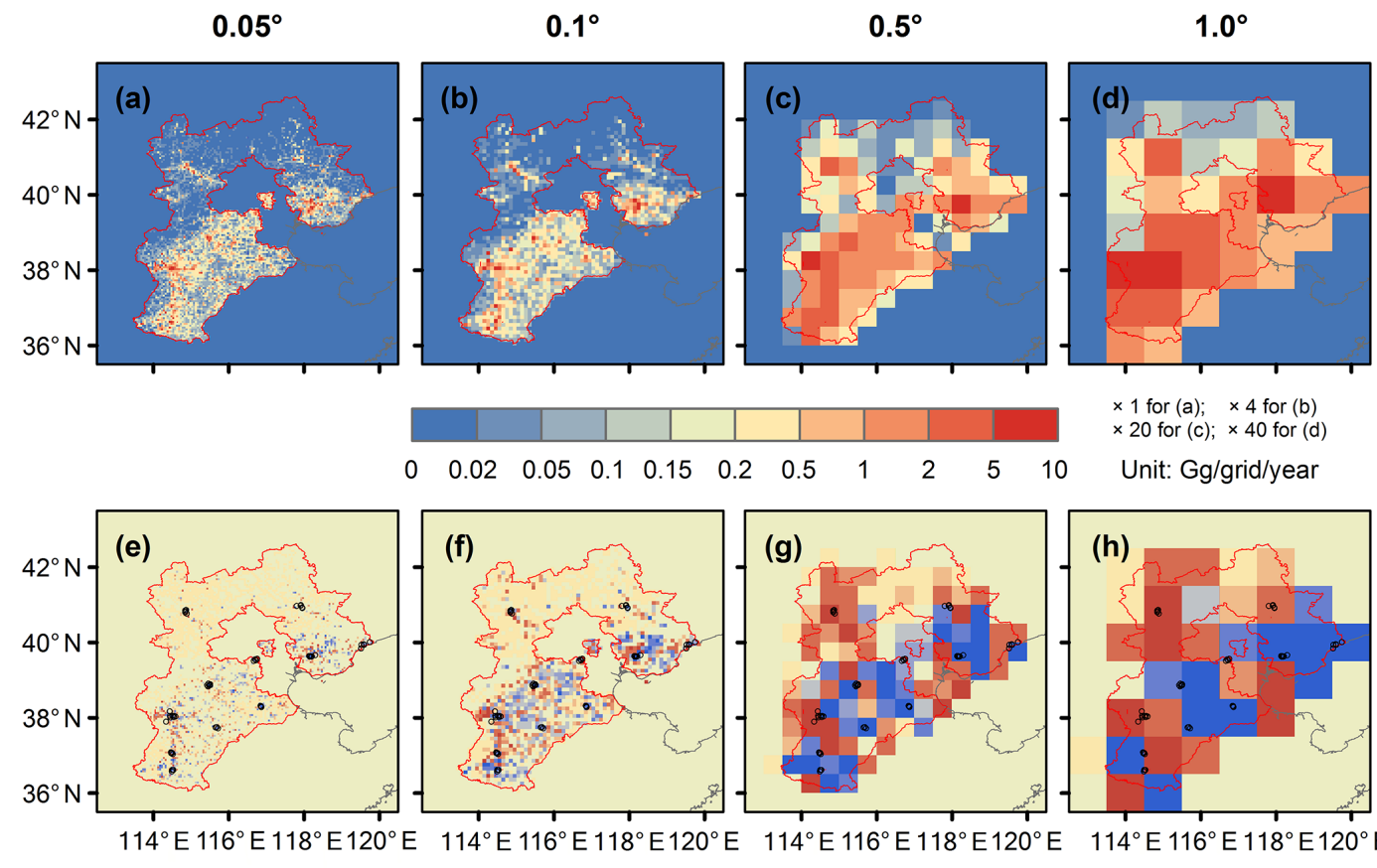

$\times 20$ for $(c) ; \times 40$ for $(d)$

Unit: $\mathrm{Gg} / g$ rid/year

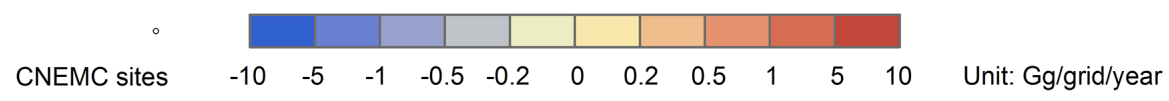

Figure 3. Comparison of the spatial distributions of gridded emissions from $\mathrm{HB}-\mathrm{EI}$ and $\mathrm{MEIC}$ at multiple resolutions. (a-d) present $\mathrm{NO} x$ emission distributions in HB-EI, and (e-h) present the differences between the two inventories (MEIC subtracted from HB-EI).

tended to overestimate emissions in urban centers but underestimate emissions in rural areas, leading to unrealistically higher urban-rural emission gradients. Following economic development and air quality control progress in China, polluted industries have tended to move away from urban centers in large cities (see Fig. 4 for the two largest cities in Hebei), resulting in the divergence of polluting industries from dense population distributions. Therefore, the use of population distribution to allocate emissions tended to overestimate the urban-rural gradients of emissions. At coarse resolutions of 0.5 and $1.0^{\circ}$, relative differences between the two inventories were smaller because the large grid covered both urban and rural regions and smoothed emission distributions.

To elucidate the variations in urban and rural areas, we analyzed the relationships between emission fluxes of $\mathrm{NO}_{x}$ 


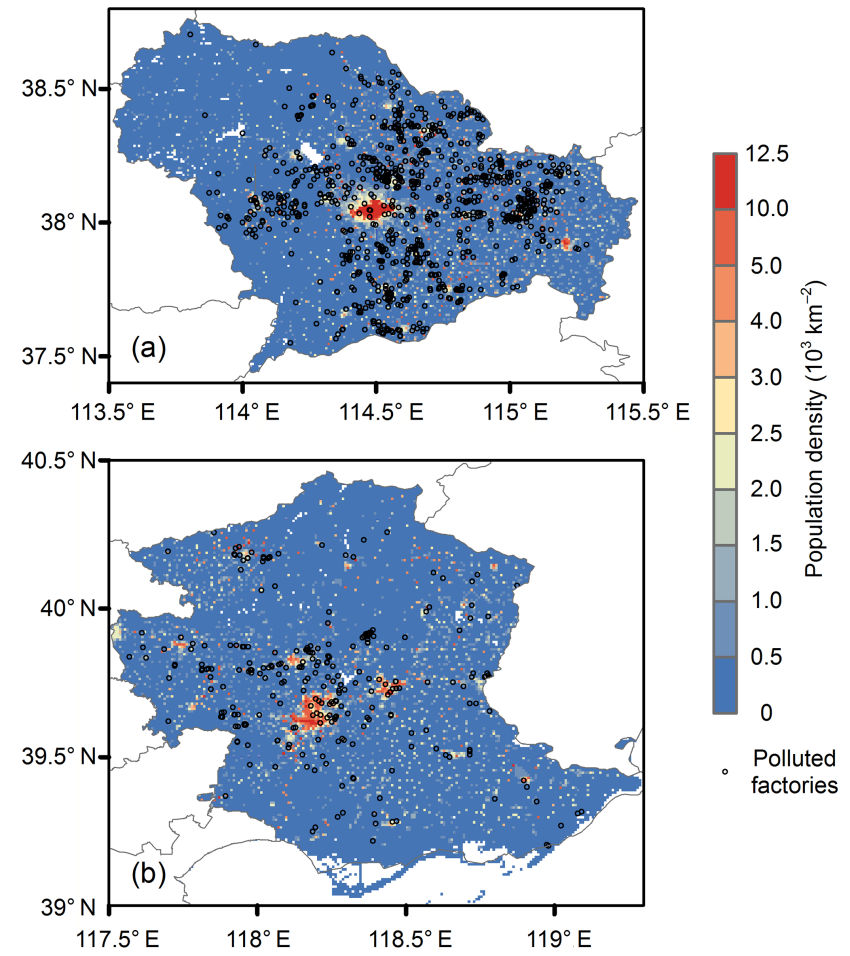

Figure 4. The spatial distributions of polluted industries and population in (a) Shijiazhuang and (b) Tangshan.

and demographic trends at multiple resolutions, as shown in Fig. 5. In HB-EI, $32 \%$ of emissions were attributed to the top $25 \%$ of the populated dense grids, as shown by the line

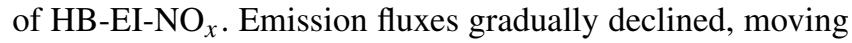
from the dense urban grids to the less dense suburban and rural grids, while emission fluxes in MEIC declined relatively sharply compared to HB-EI. This trend occurred because the proxy-based downscaling method tended to overallocate industrial emissions to urban areas, such that $42 \%$ of $\mathrm{NO}_{x}$ emissions was distributed to populated grids in the upper quartile, $10 \%$ higher than HB-EI, which resulted in larger urban-rural gradients. This pattern was evident at the finer scales given that the $\mathrm{NO}_{x}$ emission fluxes from the $10 \%$ most densely populated grids were $46-140 \%$ higher than those of HB-EI at 0.05 and $0.1^{\circ}$. At coarse resolutions, the urban and rural areas were aggregated with evenly distributed emissions. Therefore, both HB-EI-NO $x$ and MEIC-NO $x$ approached the $1: 1$ line at 0.5 and $1.0^{\circ}$ and exhibited similar emission flux patterns that were not influenced by spatial allocation biases.

Urban-scale models have emerged in response to a critical need for fine-scale modeling. However, the proxy-based downscaling method over-allocates emissions to urban centers, producing artificial emission hotspots that can result in biases in high-resolution models. When estimated as population-weighted exposures, the health risks induced by air pollution may also be overestimated due to the colloca- tion of gridded emissions with dense populations. We evaluate how uncertainties in fine-scale gridded emissions influence air pollution modeling in the next section.

\subsection{Resolution dependence of biases in air pollution modeling}

The uncertainties in gridded emission inventories induced by the proxy-based method can affect the biases of chemical transport modeling. This bias propagation was quantified by comparing performance of the WRF-CMAQ model with the MEIC (S1) and HB-EI (S2) emission inputs. The comparison was conducted at 36,12 , and $4 \mathrm{~km}$ resolutions, which roughly corresponded to the $0.5-0.05^{\circ}$ grid sizes discussed above.

For the densest urban areas, the finer-scale simulations predicted higher concentrations of air pollutants due to concentrated emissions (Fig. 6). This enhancement led to better agreement with the observations, as demonstrated by the $\mathrm{S} 2$ simulation moving from 36 to $4 \mathrm{~km}$. Higher concentrations modeled at finer scales were also observed in the $\mathrm{S} 1$ simulation, but $\mathrm{S} 1$ tended to introduce higher positive biases rather than better performances. This tendency was likely due to the over-allocated urban emissions produced by the proxy-based downscaling method. Compared to bottom-up inventories, the use of proxy-based emissions produced similar modeling results, with biases of 3-13\% in predicting surface concentrations of different pollutants at $36 \mathrm{~km}$ resolution. At 12 and $4 \mathrm{~km}$, the major pollutants modeled by proxy-based inventories were overestimated by $28-114 \%$ and $\mathrm{O}_{3}$ was underestimated by $17 \%$ due to the enhanced titration effect caused by concentrated $\mathrm{NO}_{x}$ emissions. The finer-scale modeling using proxy-based emissions introduced additional 8-73\% biases compared with bottom-up inventories. This finding suggested that urban-scale modeling efforts at $\sim 10 \mathrm{~km}$ cannot achieve corresponding accuracies until factory-level inventories are used. Regarding the emission spatial biases (see Sect. 3.2), the proxy-based downscaled emissions were appropriate for modeling at the global and regional scales (e.g., $0.25-0.5^{\circ}$ or $36 \mathrm{~km}$ in this case study), while they could cause larger biases for finer resolutions on the urban scale.

Figure S1 in the Supplement presents the spatial distribution of modeled surface concentrations for primary pollutants. The $\mathrm{S} 1$ simulation predicted higher $\mathrm{NO}_{2}$ and $\mathrm{SO}_{2}$ in the south-central part of the province but lower concentrations in the southwest. The densest cities in Hebei are located in the former region, and the industrial district along the Taihang Shan is located in the latter. The proxy-based downscaling method allocated more emissions to the populated regions, resulting in higher estimates of air pollution levels in the densest cities. Compared to bottom-up emissions, the modeling surface concentrations of air pollutants in urban areas were approximately $20-50 \%$ higher for the $36 \mathrm{~km}$ domain and were much higher at 12 and $4 \mathrm{~km}$ (see Fig. 7). The bias level was influenced by the size of cities. The cities with 

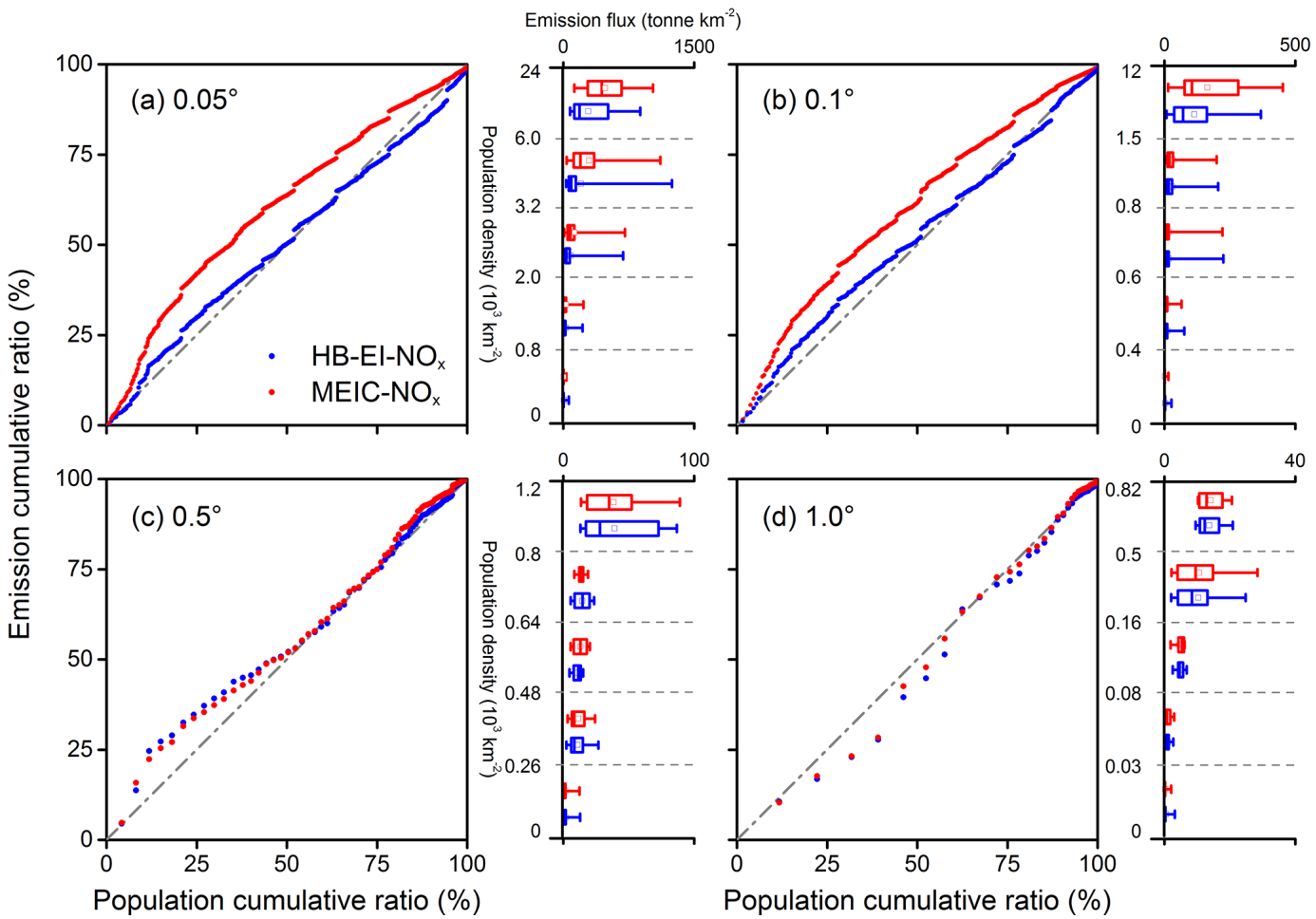

Figure 5. Cumulative ratio of emissions by population density spanning the resolutions of (a) $0.05^{\circ}$, (b) $0.1^{\circ}$, (c) $0.5^{\circ}$, and (d) $1.0^{\circ}$. The population is sorted according to descending numbers of people along the $x$ axis.
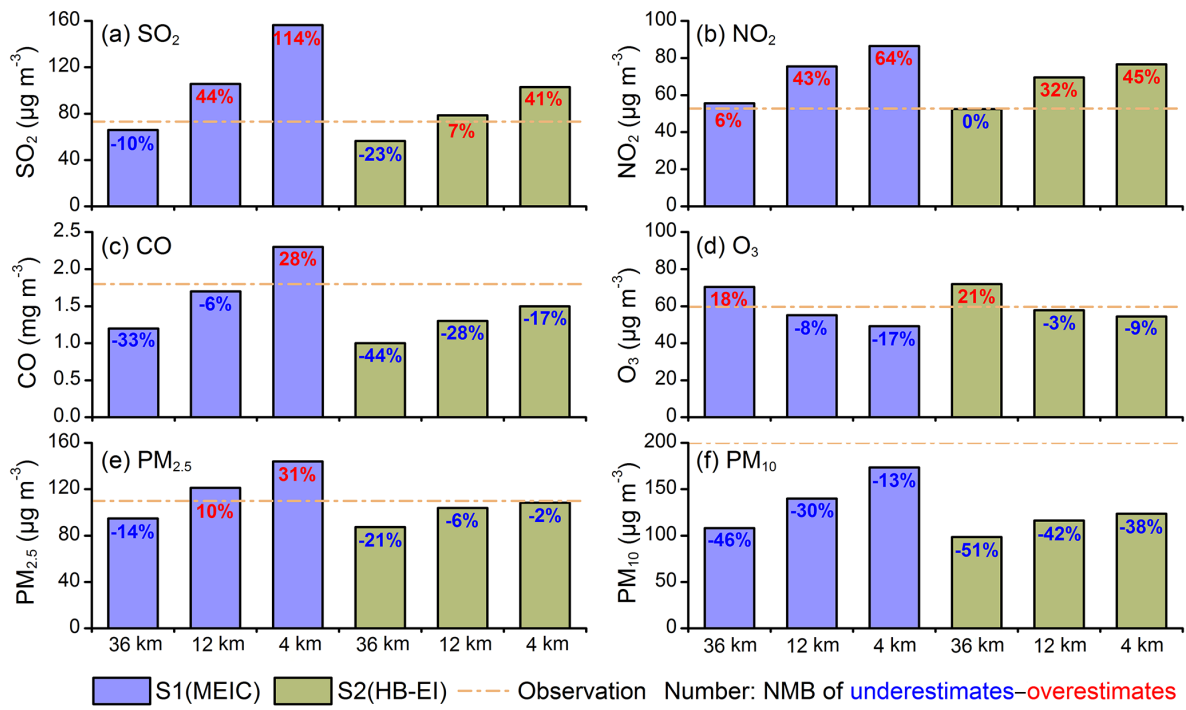

Figure 6. Evaluations against in situ measurements for atmospheric modeling using MEIC and HB-EI inventories at 36, 12, and $4 \mathrm{~km}$. The air pollutants used for evaluation include (a) $\mathrm{SO}_{2}$, (b) $\mathrm{NO}_{2}$, (c) $\mathrm{CO}$, (d) $\mathrm{O}_{3}$, (e) $\mathrm{PM}_{2.5}$, and (f) $\mathrm{PM}_{10}$.

large populations and industries tended to experience rapid urbanization, with people gathering in the urban centers and polluted industries moving outward. The modeling discrepancies of the two largest cities in Hebei (i.e., Tangshan and Shijiazhuang) were as large as 100-200\%. The small cities presented scattered distributions for both populations and in- dustries and exhibited smaller differences when using population to distribute emissions.

Figure S2 in the Supplement presents the spatial distribution of modeled $\mathrm{PM}_{2.5}$ and $\mathrm{O}_{3}$ concentrations. The $\mathrm{S} 1$ simulation tended to predict an $18-55 \%$ higher $\mathrm{PM}_{2.5}$ in the densely populated regions but a $30-110 \%$ lower $\mathrm{PM}_{2.5}$ in the 


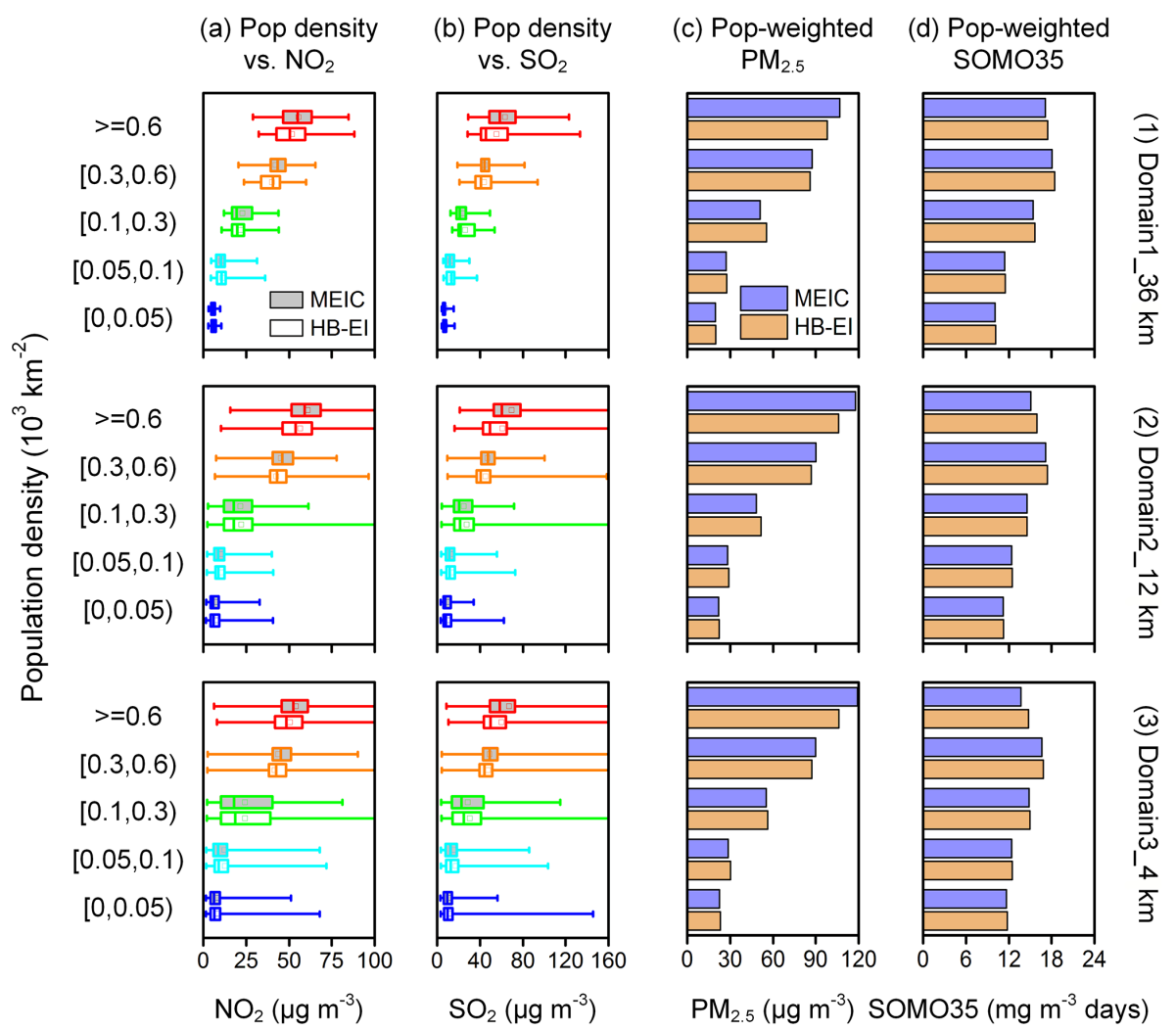

Figure 7. Air pollution distributions and exposures by population density at 36,12 , and $4 \mathrm{~km}$ : (a) $\mathrm{NO}_{2}$, (b) $\mathrm{SO}_{2}$, (c) population-weighted $\mathrm{PM}_{2.5}$, and (d) population-weighted SOMO35. Note that the SOMO35 is used to evaluate the health risk of $\mathrm{O}_{3}$ according to Amann et al. (2008).

less dense regions. The differences were slightly smaller than those found in the primary pollutants because of the nonlinear particle formation processes and long-range regional transport. For $\mathrm{O}_{3}$, the enhanced titration by $\mathrm{NO}$ due to concentrated emissions resulted in negative biases. The $\mathrm{S} 1$ simulation predicted $12-30 \%$ lower $\mathrm{O}_{3}$ in the dense regions but $16-35 \%$ higher $\mathrm{O}_{3}$ in the less dense regions. When estimated as population-weighted exposures and averaged within the areas with a population density over $600 \mathrm{~km}^{-2}$ (see Fig. 7), the $\mathrm{PM}_{2.5}$ exposures tended to be $10-20 \%$ higher, whereas the $\mathrm{O}_{3}$ exposures tended to be $10-15 \%$ lower. In the urban centers, the population exposures to $\mathrm{PM}_{2.5}$ and $\mathrm{O}_{3}$ were biased at rates as high as $50-100 \%$. The overestimated exposures of $\mathrm{PM}_{2.5}$ associated with the underestimated exposures of $\mathrm{O}_{3}$ suggested that more effort is needed to evaluate air pollution health risks on the urban scale. The uncertainties in gridded emissions comprised important uncertainties in health risk assessment.

\section{Discussion}

\subsection{Sensitivity to different proxies}

The proxy-based spatial allocation method assumed linear correlations between emission intensities and spatial proxy densities within a given district. To investigate the sensitivity of the assumption to spatial proxies, we evaluated the spatial correlations between the gridded emissions of HBEI and different spatial proxies (see Fig. 8). We concluded that the spatial correlation was enhanced significantly with increasing grid size, which was not sensitive to spatial proxy type. The grid size of $0.25^{\circ}$ roughly corresponded to the correlation coefficient of 0.5 . At coarse resolutions (grid size larger than $0.25^{\circ}$ ), good spatial correlations were found for different proxies across all pollutants. However, the correlation worsened when the spatial resolutions grew, except for pollutants dominated by nonpoint sources that were correlated with their allocating proxies (e.g., $\mathrm{NH}_{3}$ vs. rural population). Due to the discrepancies in emission source composition, the air pollutants presented different distribution patterns (see Fig. 8). Compared to nonpoint source emissions (e.g., $\mathrm{NH}_{3}$, VOCs, OC), the pollutants dominated by point sources (e.g., TSP, $\mathrm{CO}_{2}, \mathrm{SO}_{2}$ ) showed relatively poor cor- 


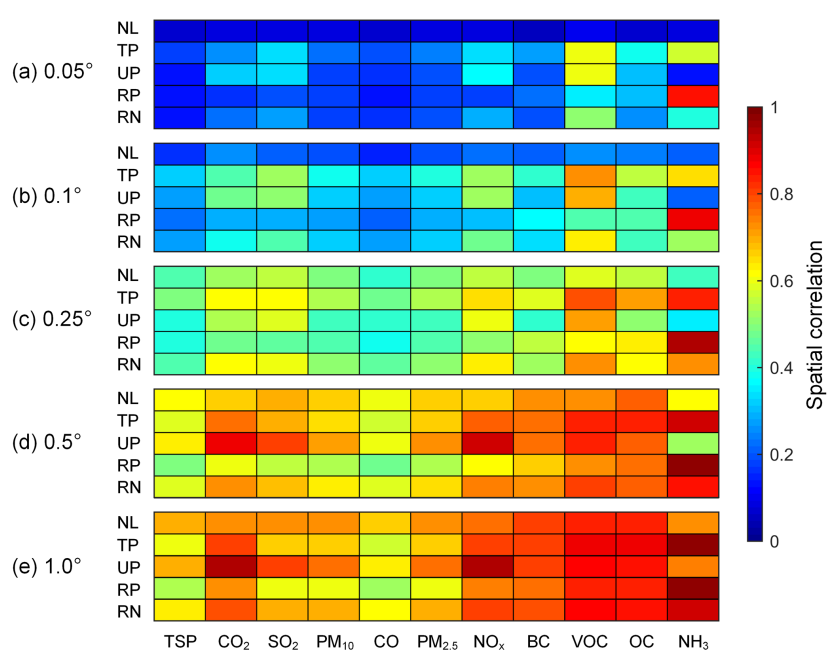

Figure 8. Spatial correlations between gridded emissions of HB-EI and various spatial proxies at the resolutions of (a) $0.05^{\circ}$, (b) $0.1^{\circ}$, (c) $0.25^{\circ}$, (d) $0.5^{\circ}$, and (e) $1.0^{\circ}$. The pollutants are sorted according to descending contribution of point-source emissions from left to right. NL: nighttime light (http://ngdc.noaa.gov/eog/dmsp/ downloadV4composites.html), TP: total population, UP: urban population, RP: rural population (population data (Oak Ridge National Laboratory, 2013) with urban-rural extents (Schneider et al., 2009), RN: road network (Zheng et al., 2014).

relations with spatial proxies. This result was not very sensitive to spatial proxy type. For example, changing allocators caused the correlation coefficient to vary only between 0.07 and 0.18 for TSP at $0.05^{\circ}$. This pattern arose because point sources have been increasingly sited away from urban areas, a phenomenon that was difficult to represent by spatial proxy distribution. In contrast, the pollutant distributions of nonpoint sources were sensitive to spatial proxies at resolutions finer than $0.25^{\circ}$ because the pollutants allocated with one proxy were clearly correlated with this proxy but uncorrelated with other proxies on fine scales. However, all the proxies tended to present similar spatial distributions on large scales, demonstrated by the correlation coefficient of almost 1 at resolutions coarser than $0.25^{\circ}$. The findings above suggest that the underlying assumption inherent in the proxybased emission allocation process is potentially valid on a coarse scale but is highly suspect on scales finer than $0.25^{\circ}$.

We evaluated the spatial correlations of HB-EI with different proxies by sector, as shown in Fig. 9. $\mathrm{NO}_{x}$ is shown as an example (the results for other pollutants are similar). Because the locations of point sources were decoupled from spatial proxies at fine resolutions, power plant and industrial emissions presented poor correlations $\left(R^{2}<0.2\right)$ with various spatial proxies when grid size was smaller than $0.5^{\circ}$. The decoupling effect was weakened when grids were aggregated to $0.5^{\circ}$ or higher, and consistent spatial patterns were found between emissions from point sources and different spatial proxies. The residential and transportation emissions were sensitive to proxy selections on finer scales, which were affected by the allocating proxies used by the two sectors. When grids were aggregated to $0.25^{\circ}$ or higher, these nonpoint source emissions showed consistent spatial distributions regardless of spatial proxies. For total emissions, the variation of spatial correlation between gridded emissions and proxies was narrowed for grids larger than $0.25^{\circ}$. Therefore, the proxy-based downscaling method tended to introduce large errors on scales finer than $0.25^{\circ}$, where local patterns in the distributed point sources dominated over diffuse nonpoint sources, which have not yet been reproduced by any spatial proxy on finer scales.

The findings above imply that spatial proxies should be used with caution. When building regional and global gridded emissions (typically larger than $0.25^{\circ}$ ), the two proxies of total population and nighttime light performed slightly better than the other proxies did. These two proxies correlated well with gridded emissions, while other proxies such as urban population, rural population, and road network had several limitations. Urban population tended to over-allocate emissions to urban areas. Rural population had poor spatial correlation with gridded emissions. The spatial distribution patterns of road networks were not suitable for emission allocation except for those from vehicles. When mapping emissions at higher resolutions (e.g., finer than $0.25^{\circ}$ ), the proxies of total population and nighttime light were poorly correlated with gridded emissions dominated by point sources, and the spatial distributions of nonpoint source emissions were very sensitive to spatial proxies. In this case, the bottom-up method must be used instead of the proxy-based method to improve the spatial representation of emission distributions.

\subsection{Sensitivity to point sources}

The bottom-up method estimated emissions for each individual facility as a point source to improve the accuracy of inventory. The point source estimates constituted the main difference between MEIC and HB-EI, demonstrated by the discrepancy in point source shares (Fig. 2). Compared to MEIC, the distinct improvement of HB-EI was to treat all facilities from the industry sector as point sources in addition to a minor improvement in province-to-county emission allocation. These changes produced better agreements with in situ observations when used for urban-scale modeling. At $4 \mathrm{~km}$ resolution, the bottom-up inventory of HB-EI reduced biases by 8$73 \%$ in predicting the surface concentrations of different air pollutants. To evaluate the sensitivity of fine-scale modeling to point source estimates, we conducted a sensitivity analysis by slightly reducing the contributions of point sources, an analysis denoted by S3 (see Sect. 2.2.2). The extent to which fine-scale modeling influenced the modeling performance highlighted the implications for point source estimates and the role high-resolution emission mapping played in fine-scale modeling. 

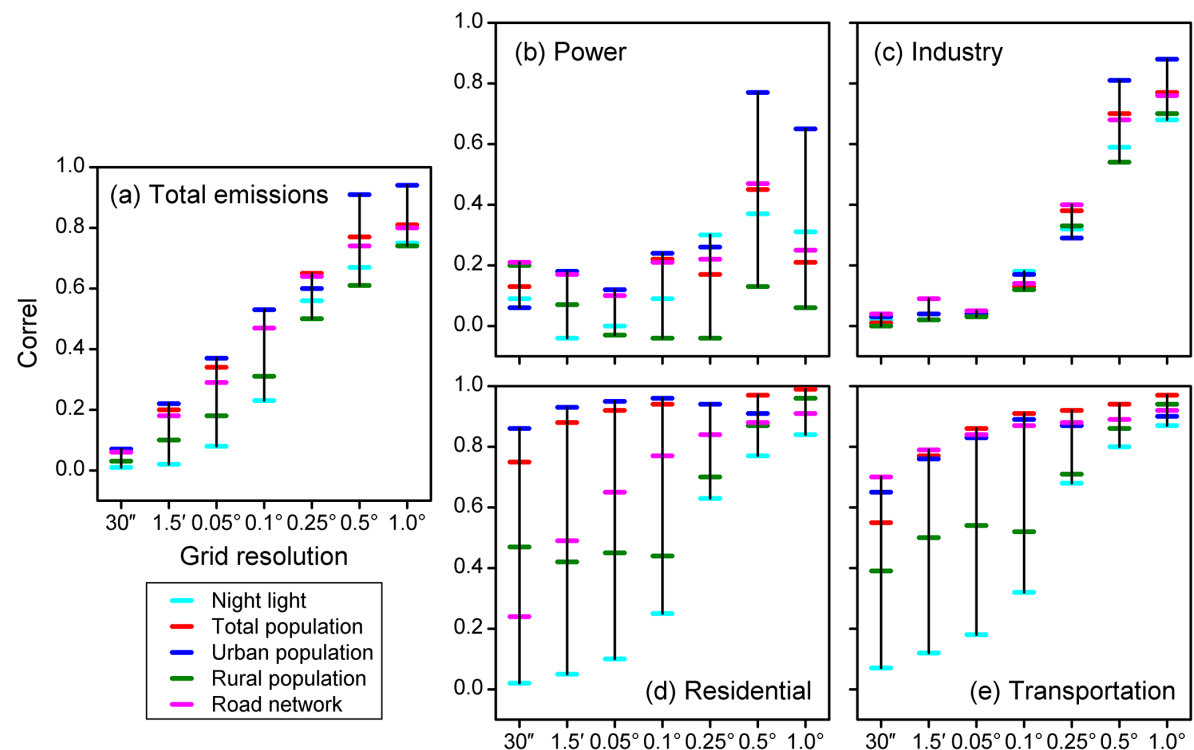

Figure 9. Sector-specific spatial correlation between $\mathrm{NO}_{x}$ emissions from $\mathrm{HB}-\mathrm{EI}$ and allocating proxies spanning resolutions from $30^{\prime \prime}$ to $1.0^{\circ}$. (a) Total emissions, (b) power sector, (c) industry sector, (d) residential sector, and (e) transportation sector.

Table 3. Sensitivity analysis results.

\begin{tabular}{|c|c|c|c|c|c|c|c|c|c|c|c|c|}
\hline \multicolumn{13}{|c|}{ Emissions by source type in MEIC, HB-EI, and adjusted ${ }^{\mathrm{a}}(\mathrm{Gg})$} \\
\hline \multicolumn{2}{|c|}{ Source type } & TSP & $\mathrm{CO}_{2}$ & $\mathrm{SO}_{2}$ & $\mathrm{PM}_{10}$ & $\mathrm{CO}$ & $\mathrm{PM}_{2.5}$ & $\mathrm{NO}_{x}$ & $\mathrm{BC}$ & VOCs & OC & $\mathrm{NH}_{3}$ \\
\hline \multirow[t]{3}{*}{ MEIC } & Point & 57 & 180673 & 228 & 55 & 269 & 36 & 456 & 0 & 4 & 0 & 0 \\
\hline & Nonpoint & 2594 & 585511 & 1136 & 1175 & 15988 & 834 & 1008 & 127 & 1394 & 215 & 543 \\
\hline & Mobile & 26 & 61011 & 9 & 26 & 578 & 24 & 522 & 13 & 113 & 4 & 4 \\
\hline \multirow[t]{3}{*}{ HB-EI } & Point & 2302 & 675974 & 1102 & 920 & 11659 & 602 & 1267 & 66 & 538 & 74 & 18 \\
\hline & Nonpoint & 349 & 90210 & 262 & 310 & 4598 & 268 & 197 & 61 & 860 & 141 & 525 \\
\hline & Mobile & 26 & 61011 & 9 & 26 & 578 & 24 & 522 & 13 & 113 & 4 & 4 \\
\hline \multirow[t]{3}{*}{ Adjusted } & Point & 1606 & 479773 & 810 & 666 & 9933 & 447 & 675 & 41 & 257 & 50 & 11 \\
\hline & Nonpoint & 1045 & 286411 & 554 & 564 & 6324 & 423 & 789 & 86 & 1141 & 165 & 532 \\
\hline & Mobile & 26 & 61011 & 9 & 26 & 578 & 24 & 522 & 13 & 113 & 4 & 4 \\
\hline \multicolumn{13}{|c|}{ Model evaluation $^{\mathrm{b}}$ of domain 3 for $\mathrm{S} 1, \mathrm{~S} 2$, and $\mathrm{S} 3^{\mathrm{c}}$} \\
\hline \multirow[t]{2}{*}{ Pollutants } & $\mathrm{Obs}^{\mathrm{d}}$ & & $\operatorname{Sim}^{\mathrm{d}}$ & & & & $\mathrm{MB}^{\mathrm{d}}$ & & & & $\operatorname{VMB}(\%)$ & \\
\hline & I & S1 & S2 & S3 & & S1 & S2 & S3 & & S1 & S2 & S3 \\
\hline $\mathrm{SO}_{2}$ & 69.2 & 149.6 & 106 & 107.3 & & 80.3 & 36.7 & 38 & & 147.8 & 53 & 54.9 \\
\hline $\mathrm{NO}_{2}$ & 52.5 & 86.6 & 75.4 & 82.2 & & 34.1 & 22.9 & 29.7 & & 80.5 & 43.6 & 56.6 \\
\hline $\mathrm{CO}$ & 1.9 & 2.4 & 1.5 & 1.4 & & 0.5 & -0.4 & -0.5 & & 18.1 & -19.9 & -24.2 \\
\hline $\mathrm{O}_{3}$ & 60.8 & 47.7 & 53.3 & 48.9 & & -13.2 & -7.7 & -12.1 & & -21.6 & -12.6 & -19.8 \\
\hline $\mathrm{PM}_{2.5}$ & 105.4 & 141 & 107.9 & 112.8 & & 35.6 & 2.5 & 7.4 & & 34 & 2.4 & 7 \\
\hline $\mathrm{PM}_{10}$ & 202.1 & 174.2 & 125.8 & 132.7 & & -28 & -76.3 & -69.4 & & -16 & -37.7 & -34.3 \\
\hline
\end{tabular}

${ }^{\text {a }}$ Decrease point source shares by $\sim 20 \%$ on the basis of the HB-EI inventory.

$\mathrm{b}$ The modeling evaluation is based on simulations from January, April, July, and October

${ }^{c}$ S1 used MEIC emissions, S2 used HB-EI emissions, and S3 used adjusted emissions.

d The units for $\mathrm{SO}_{2}, \mathrm{NO}_{2}, \mathrm{O}_{3}, \mathrm{PM}_{2.5}$, and $\mathrm{PM}_{10}$ are $\mu \mathrm{g} \mathrm{m}^{-3}$, and the unit for $\mathrm{CO}$ is $\mathrm{mg} \mathrm{m}^{-3}$.

For S3, we converted small industrial boilers $(\leq 24.5 \mathrm{MW})$ in HB-EI to nonpoint sources for a sensitivity test by aggregating the emissions into provincial totals and then distributing them into grid cells like MEIC. The emission shares of point sources were reduced by $\sim 20 \%$ for almost all pollutants (Table 3). The modeling biases that used this adjusted inventory (S3) fell between those from the MEIC-based simulation (S1) and HB-EI-based simulation (S2). The normal- 
ized mean biases of the criterion pollutants were approximately $5-15 \%$ higher than those produced by S2 due to the inclusion of $\sim 20 \%$ fewer point sources, whereas they were $18-90 \%$ lower than those produced by S1 due to the inclusion of $\sim 50 \%$ more point sources. This difference suggested that the spatial biases tended to decline significantly as more point sources were included. The improvement of modeling biases roughly corresponded to the increased contributions of point sources to emissions.

\section{Concluding remarks}

In this study, we assessed the resolution dependence of uncertainties in gridded emission inventories, using Hebei, China, as a case. The inherent uncertainties involved in emission distributions caused systematic biases in both the emission flux patterns and subsequent chemical transport modeling. A companion paper of this work also highlighted the influence of allocating proxies on spatial representation of gridded emissions (Geng et al., 2016). In the case of Hebei, China, the proxy-based downscaling method tended to overallocate emissions to the urban center. For example, the $\mathrm{NO}_{x}$ emission fluxes from the $10 \%$ most densely populated grids tended to be overestimated by $46-140 \%$ at 0.1 and $0.05^{\circ}$ in this case study. This effect was demonstrated by the modeling performance of the CMAQ model, in which the modeling biases of different pollutants using a proxy-based inventory were $8-73 \%$ higher than using bottom-up inventories on a fine scale (12 and $4 \mathrm{~km}$ ). The modeling biases induced by uncertainties in gridded emissions caused population exposures of $\mathrm{PM}_{2.5}$ to be overestimated and $\mathrm{O}_{3}$ to be underestimated in urban areas.

In the proxy-based inventory, the inherent assumption of spatial correlation between emissions and allocating proxies was highly suspect on an urban scale (grid sizes smaller than $0.25^{\circ}$ in this case study). This lack of validity was caused by polluted industries increasingly moving away from urban centers, a phenomenon that resulted in a decoupling of emissions from spatial proxies on finer scales. The gridded emissions on a coarse scale tended to aggregate urban, suburban, and rural areas and smooth emission distributions. They also tended to weaken the decoupling effect. Extensive use of point sources could improve the accuracy of gridded emissions, demonstrated by the improvement of modeling performance as the contribution of point sources increased. We concluded that proxy-based inventories are capable of supporting regional and global models (larger than $0.25^{\circ}$ in this case study); however, to support urban-scale models with accurate emission inputs, bottom-up inventories with exact locations of emitting facilities should be developed instead.

\section{Data availability}

Research data are available upon request to the corresponding author Qiang Zhang (qiangzhang@ @ tsinghua.edu.cn).

\section{The Supplement related to this article is available online at doi:10.5194/acp-17-921-2017-supplement.}

Acknowledgement. This work was supported by China's National Basic Research Program (2014CB441301), the National Key R\&D Program (2016YFC0201506), the National Science Foundation of China (41625020 and 41571130032), the National Key Technology R\&D Program (2014BAC16B03 and 2014BAC21B02), and the public welfare program of China's Ministry of Environmental Protection (201509014).

Edited by: G. Frost

Reviewed by: two anonymous referees

\section{References}

Amann, M., Derwent, D., Forsberg, B., Hänninen, O., Hurley, F., Krzyzanowski, M., Leeuw, F., Liu, S., Mandin, C., Schneider, J., Schwarze, P., and Simpson, D.: Health risks of ozone from longrange transboundary air pollution, WHO Regional Office for Europe, available at: http://www.euro.who.int/_data/assets/pdf_ file/0005/78647/E91843.pdf (last access: March 2016), 2008.

Asefi-Najafabady, S., Rayner, P. J., Gurney, K. R., McRobert, A., Song, Y., Coltin, K., Huang, J., Elvidge, C., and Baugh, K.: A multiyear, global gridded fossil fuel $\mathrm{CO}_{2}$ emission data product: Evaluation and analysis of results, J. Geophys. Res.-Atmos., 119, 10213-10231, doi:10.1002/2013JD021296, 2014.

Bey, I., Jacob, D. J., Yantosca, R. M., Logan, J. A., Field, B. D., Fiore, A. M., Li, Q., Liu, H. Y., Mickley, L. J., and Schultz, M. G.: Global modeling of tropospheric chemistry with assimilated meteorology: Model description and evaluation, J. Geophys. Res.-Atmos., 106, 23073-23095, doi:10.1029/2001JD000807, 2001.

Boersma, K. F., Eskes, H. J., Dirksen, R. J., van der A, R. J., Veefkind, J. P., Stammes, P., Huijnen, V., Kleipool, Q. L., Sneep, M., Claas, J., Leitão, J., Richter, A., Zhou, Y., and Brunner, D.: An improved tropospheric $\mathrm{NO}_{2}$ column retrieval algorithm for the Ozone Monitoring Instrument, Atmos. Meas. Tech., 4, 19051928, doi:10.5194/amt-4-1905-2011, 2011.

Chang, J. S., Brost, R. A., Isaksen, I. S. A., Madronich, S., Middleton, P., Stockwell, W. R., and Walcek, C. J.: A threedimensional Eulerian acid deposition model: Physical concepts and formulation, J. Geophys. Res.-Atmos., 92, 14681-14700, doi:10.1029/JD092iD12p14681, 1987.

Fountoukis, C. and Nenes, A.: ISORROPIA II: a computationally efficient thermodynamic equilibrium model for $\mathrm{K}^{+}-\mathrm{Ca}^{2+}$ $\mathrm{Mg}^{2+}-\mathrm{NH}^{4+}-\mathrm{Na}^{+}-\mathrm{SO}_{4}^{2-}-\mathrm{NO}_{3-}-\mathrm{Cl}^{-}-\mathrm{H}_{2} \mathrm{O}$ aerosols, Atmos. Chem. Phys., 7, 4639-4659, doi:10.5194/acp-7-4639-2007, 2007. 
Gately, C. K., Hutyra, L. R., Wing, I. S., and Brondfield, M. N.: A Bottom up Approach to on-Road $\mathrm{CO}_{2}$ Emissions Estimates: Improved Spatial Accuracy and Applications for Regional Planning, Environ. Sci. Technol., 47, 2423-2430, doi:10.1021/es304238v, 2013.

Gately, C. K., Hutyra, L. R., and Sue Wing, I.: Cities, traffic, and $\mathrm{CO}_{2}$ : A multidecadal assessment of trends, drivers, and scaling relationships, P. Natl. Acad. Sci. USA, 112, 4999-5004, doi:10.1073/pnas.1421723112, 2015.

Geng, G., Zhang, Q., Martin, R., Lin, J., Huo, H., Zheng, B., Wang, $\mathrm{S}$., and He, K.: Impact of spatial proxies on the representation of bottom-up emission inventories: A satellite-based analysis, Atmos. Chem. Phys. Discuss., doi:10.5194/acp-2016-905, in review, 2016.

Gurney, K. R., Mendoza, D. L., Zhou, Y., Fischer, M. L., Miller, C. C., Geethakumar, S., and de la Rue du Can, S.: High Resolution Fossil Fuel Combustion $\mathrm{CO}_{2}$ Emission Fluxes for the United States, Environ. Sci. Technol., 43, 5535-5541, doi:10.1021/es900806c, 2009.

Henderson, B. H., Akhtar, F., Pye, H. O. T., Napelenok, S. L., and Hutzell, W. T.: A database and tool for boundary conditions for regional air quality modeling: description and evaluation, Geosci. Model Dev., 7, 339-360, doi:10.5194/gmd-7-3392014, 2014.

Lei, Y., Zhang, Q., He, K. B., and Streets, D. G.: Primary anthropogenic aerosol emission trends for China, 1990-2005, Atmos. Chem. Phys., 11, 931-954, doi:10.5194/acp-11-931-2011, 2011.

Li, M., Zhang, Q., Kurokawa, J., Woo, J.-H., He, K. B., Lu, Z., Ohara, T., Song, Y., Streets, D. G., Carmichael, G. R., Cheng, Y. F., Hong, C. P., Huo, H., Jiang, X. J., Kang, S. C., Liu, F., Su, H., and Zheng, B.: MIX: a mosaic Asian anthropogenic emission inventory for the MICS-Asia and the HTAP projects, Atmos. Chem. Phys. Discuss., 15, 34813-34869, doi:10.5194/acpd-1534813-2015, 2015.

Liu, F., Zhang, Q., Tong, D., Zheng, B., Li, M., Huo, H., and He, K. B.: High-resolution inventory of technologies, activities, and emissions of coal-fired power plants in China from 1990 to 2010, Atmos. Chem. Phys., 15, 13299-13317, doi:10.5194/acp15-13299-2015, 2015.

McDonald, B. C., McBride, Z. C., Martin, E. W., and Harley, R. A.: High-resolution mapping of motor vehicle carbon dioxide emissions, J. Geophys. Res.-Atmos., 119, 5283-5298, doi:10.1002/2013JD021219, 2014.

National Bureau of Statistics: China Statistical Yearbook for Regional Economy 2014, China Statistics Press, Beijing, China, 2014.

Oak Ridge National Laboratory (ORNL): LandScan Global Population Database, Oak Ridge National Laboratory, Oak Ridge, TN, USA, 2013.

Oda, T. and Maksyutov, S.: A very high-resolution $(1 \mathrm{~km} \times 1 \mathrm{~km})$ global fossil fuel $\mathrm{CO}_{2}$ emission inventory derived using a point source database and satellite observations of nighttime lights, Atmos. Chem. Phys., 11, 543-556, doi:10.5194/acp-11-543-2011, 2011.
Raupach, M. R., Rayner, P. J., and Paget, M.: Regional variations in spatial structure of nightlights, population density and fossil-fuel $\mathrm{CO}_{2}$ emissions, Energ. Policy, 38, 4756-4764, doi:10.1016/j.enpol.2009.08.021, 2010.

Rayner, P. J., Raupach, M. R., Paget, M., Peylin, P., and Koffi, E.: A new global gridded data set of $\mathrm{CO}_{2}$ emissions from fossil fuel combustion: Methodology and evaluation, J. Geophys. Res.-Atmos., 115, D19306, doi:10.1029/2009JD013439, 2010.

Schneider, A., Friedl, M. A., and Potere, D.: A new map of global urban extent from MODIS satellite data, Environ. Res. Lett., 4, 044003, doi:10.1088/1748-9326/4/4/044003, 2009.

Walcek, C. J. and Taylor, G. R.: A Theoretical Method for Computing Vertical Distributions of Acidity and Sulfate Production within Cumulus Clouds, J. Atmos. Sci., 43, 339-355, doi:10.1175/1520-0469(1986)043<0339:ATMFCV>2.0.CO;2, 1986.

Wang, R., Tao, S., Ciais, P., Shen, H. Z., Huang, Y., Chen, H., Shen, G. F., Wang, B., Li, W., Zhang, Y. Y., Lu, Y., Zhu, D., Chen, Y. C., Liu, X. P., Wang, W. T., Wang, X. L., Liu, W. X., Li, B. G., and Piao, S. L.: High-resolution mapping of combustion processes and implications for $\mathrm{CO}_{2}$ emissions, Atmos. Chem. Phys., 13, 5189-5203, doi:10.5194/acp-13-5189-2013, 2013.

Whitten, G. Z., Heo, G., Kimura, Y., McDonald-Buller, E., Allen, D. T., Carter, W. P. L., and Yarwood, G.: A new condensed toluene mechanism for Carbon Bond: CB05-TU, Atmos. Environ., 44, 5346-5355, doi:10.1016/j.atmosenv.2009.12.029, 2010.

Zhang, Q., Streets, D. G., He, K., Wang, Y., Richter, A., Burrows, J. P., Uno, I., Jang, C. J., Chen, D., Yao, Z., and Lei, Y.: $\mathrm{NO}_{x}$ emission trends for China, 1995-2004: The view from the ground and the view from space, J. Geophys. Res.-Atmos., 112, D22306, doi:10.1029/2007JD008684, 2007.

Zhang, Q., Streets, D. G., Carmichael, G. R., He, K. B., Huo, H., Kannari, A., Klimont, Z., Park, I. S., Reddy, S., Fu, J. S., Chen, D., Duan, L., Lei, Y., Wang, L. T., and Yao, Z. L.: Asian emissions in 2006 for the NASA INTEX-B mission, Atmos. Chem. Phys., 9, 5131-5153, doi:10.5194/acp-9-5131-2009, 2009.

Zhao, Y., Wang, S., Duan, L., Lei, Y., Cao, P., and Hao, J.: Primary air pollutant emissions of coal-fired power plants in China: Current status and future prediction, Atmos. Environ., 42, 84428452, doi:10.1016/j.atmosenv.2008.08.021, 2008.

Zheng, B., Huo, H., Zhang, Q., Yao, Z. L., Wang, X. T., Yang, X. F., Liu, H., and He, K. B.: High-resolution mapping of vehicle emissions in China in 2008, Atmos. Chem. Phys., 14, 9787-9805, doi:10.5194/acp-14-9787-2014, 2014.

Zheng, B., Zhang, Q., Zhang, Y., He, K. B., Wang, K., Zheng, G. J., Duan, F. K., Ma, Y. L., and Kimoto, T.: Heterogeneous chemistry: a mechanism missing in current models to explain secondary inorganic aerosol formation during the January 2013 haze episode in North China, Atmos. Chem. Phys., 15, 2031-2049, doi:10.5194/acp-15-2031-2015, 2015. 